\title{
Social and Behavioural Factors in Cetacean Responses to Overexploitation: Are Odontocetes Less "Resilient" Than Mysticetes?
}

\author{
Paul R. Wade, ${ }^{1}$ Randall R. Reeves, ${ }^{2}$ and Sarah L. Mesnick ${ }^{3}$ \\ ${ }^{1}$ National Marine Mammal Laboratory, Alaska Fisheries Science Center, National Oceanic and Atmospheric Administration, \\ Seattle, WA 98115, USA \\ ${ }^{2}$ Okapi Wildlife Associates, 27 Chandler Lane, Hudson, QC, Canada JOP 1 HO \\ ${ }^{3}$ Southwest Fisheries Science Center, National Marine Fisheries Service, National Oceanic and Atmospheric Administration, \\ 3333 North Torrey Pines Court, La Jolla, CA 92037, USA
}

Correspondence should be addressed to Paul R.Wade, paul.wade@noaa.gov

Received 23 January 2012; Accepted 26 April 2012

Academic Editor: Frances Gulland

Copyright () 2012 Paul R. Wade et al. This is an open access article distributed under the Creative Commons Attribution License, which permits unrestricted use, distribution, and reproduction in any medium, provided the original work is properly cited.

\begin{abstract}
Many severely depleted populations of baleen whales (Mysticeti) have exhibited clear signs of recovery whereas there are few examples in toothed whales (Odontoceti). We hypothesize that this difference is due, at least in part, to social and behavioural factors. Clearly, a part of the lack of resilience to exploitation is explained by odontocete life history. However, an additional factor may be the highly social nature of many odontocetes in which survival and reproductive success may depend on: (a) social cohesion and organization, (b) mutual defence against predators and possible alloparental care, (c) inter-generational transfer of "knowledge", and (d) leadership by older individuals. We found little evidence of strong recovery in any of the depleted populations examined. Their relatively low potential rates of increase mean that odontocete populations can be over-exploited with take rates of only a few percent per year. Exploitation can have effects beyond the dynamics of individual removals. Four species showed evidence of a decrease in birth rates following exploitation; potential mechanisms include a deficit of adult females, a deficit of adult males, and disruption of mating systems. The evidence for a lack of strong recovery in heavily exploited odontocete populations indicates that management should be more precautionary.
\end{abstract}

\section{Introduction}

In a 1993 paper, Best [1] examined increase rates in severely depleted stocks of baleen whales (Mysticeti). Of 44 that had been depleted to less than $10 \%$ of their original abundance, 12 were being adequately monitored to determine trends, and of those, ten exhibited significant positive rates of increase. In effect, Best concluded that there was no clear evidence for a "lag" in the response to protection (e.g., due to depensation or so-called "Allee effects") and that apparent delays in recovery by some stocks were more likely due to the inadequacy of monitoring effort than to impaired reproduction or recruitment failure. Further, he offered the hypothesis that in many stocks "a combination of range retraction and underestimation of the extent of depletion has hindered detection of a recovery." In the nearly 20 years since Best's analysis, a number of the 32 severely depleted stocks that he judged to have been inadequately monitored have now shown clear signs of increase. For example, there is evidence for increases in blue whale (Balaenoptera musculus) abundance [2] in the Antarctic and fin whale (Balaenoptera physalus) abundance in central California [3]. Bowhead whales (Balaena mysticetus) in eastern Canada and West Greenland are now known to be much more numerous than previously supposed and have shown clear signs of increase since 1981 off West Greenland [4].

No analysis similar to Best's for mysticetes has been carried out to examine whether severely depleted populations of toothed cetaceans, or odontocetes (Odontoceti), have shown evidence of recovery. The hypothesis developed 
in the present paper is that odontocetes are less resilient to intensive exploitation than mysticetes (whether deliberate by hunting or nondeliberate, e.g., by incidental killing in fishing gear) and that this difference is due, at least in part, to social and behavioural factors. The concept of resilience is in some respects the obverse of extinction proneness, which has become a subject of mainstream discussion in conservation biology. In general, resilience, or lack of it, is an ecological concept, whereas extinction proneness is very much a species concept. Our approach here is to consider species, or population, resilience as something that can be measured in terms of ability to recover from extreme depletion.

Clearly, a part of the lack of resilience to exploitation stems from the life history of odontocetes. Their relatively old age of first reproduction and low calving rate lead to relatively low maximum rates of increase [5-7]. Some species of baleen whales have been observed or estimated to increase at rates of $6 \%$ per year and higher (e.g., humpback whales (Megaptera novaeangliae) and gray whales (Eschrichtius robustus)), and this has obviously contributed to the strong recovery seen in some of these species [1]. In contrast, though data are admittedly scarce, there is still no evidence to show that any odontocete population can increase at a rate greater than $4 \%$ per year, and for some species it is questionable if they are capable of even that. A related factor is that the life history of long-lived animals with relatively old ages of first reproduction can create delays in recovery if exploitation has been selective for reproductive-aged animals.

However, an additional factor that may contribute to the lack of resilience seen in odontocetes is related to their social and behavioural traits. Consistent with their long evolutionary history, global dispersal and habitat specializations, odontocetes exhibit a diverse array of social systems, ranging from the relatively hierarchical and relatively stable pattern of killer whales (Orcinus orca) and sperm whales (Physeter macrocephalus), to the classic fission-fusion pattern of many dolphins (Delphinidae), to the seemingly unstructured societies of porpoises (Phocoenidae) [8]. Group sizes vary from the small social units (perhaps only 3 to 10 individuals) of transient killer whales and some beaked whales (Ziphiidae), to the intermediate-sized pods (ten to a few tens) of resident killer whales, sperm whales, and whitebeaked dolphins (Lagenorhynchus albirostris), to the large aggregations composed of hundreds or thousands of individuals characteristic of pantropical spotted (Stenella attenuata), striped (Stenella coeruleoalba), spinner (Stenella longirostris), and short-beaked common dolphins (Delphinus delphis). In at least some odontocetes, survival and reproductive success may depend on such things as (a) social cohesion and social organization, (b) mutual aid in defence against predators and possible alloparental care such as "babysitting" and communal nursing, (c) sufficient opportunities for transfer of "knowledge" (learned behaviour) from one generation to the next, and (d) leadership by older individuals that know where and when to find scarce prey resources and how to avoid high-risk circumstances (e.g., ice-entrapment, stranding, and predation). Group living has numerous potential benefits for marine mammals generally [9]. Therefore, the effects of exploitation on these social animals-for example, social disruption, fragmentation of social units, and loss of key individuals_-could be nonlinear and unpredictable, with severity contingent upon various features of the exploitation regime such as age and sex selectivity, methods of capture, seasonality, and habitat quality or integrity.

The role of social and behavioural traits in determining the cumulative effect of hunting has been shown in many terrestrial species. The removal of both matriarchs and trophy males from elephant (Loxodonta africana) populations has been shown to cause social disruption $[10,11]$, and lower fecundity has been correlated with heavy hunting in two populations, apparently because older males with large tusks are responsible for most mating in undisturbed populations [10]. In elephants, the selective killing of matriarchs for their large tusks is also thought to reduce the availability of "social knowledge" to a group or herd [11]. Similar concerns have arisen in relation to trophy hunting of ungulates, where the selective removal of alpha adult males leads to the loss of valuable genetic as well as cultural capital [12]. There are numerous terrestrial examples, where the deliberate selection by hunters for phenotypic traits has led to a loss of genetic fitness in the wildlife population $[13,14]$. Examples include the lower reproductive success of bighorn sheep (Ovis canadensis) when rams with larger horns are removed [15] and the increased occurrence of tusk-less female elephants as a result of hunting for ivory [16]. Darimont et al. [14] found average phenotypic changes in 40 populations subject to hunting to be much more rapid than changes reported in studies of naturally perturbed populations and wild populations subject to other human perturbations, outpacing them by $>300 \%$ and $50 \%$, respectively. They concluded that hunted populations show some of the most abrupt trait changes ever observed in wild populations, which include average declines of almost 20\% in sizerelated traits and shifts in life history traits of nearly $25 \%$. Additionally, they found the most rapid changes occurred in commercially exploited populations, and they cautioned that such alterations to phenotypes might also generate large and rapid changes in population and ecological dynamics including those that affect population persistence.

Trophy hunting of male ungulates and subsequently skewed sex ratios have been shown to reduce fecundity, at sex ratios ranging from 1:2 (in Soay sheep (Ovis aries) and in moose (Alces alces)) to $1: 12$ (in caribou (Rangifer tarandus)) [12]. Species with highly synchronous breeding can be particularly susceptible to this if females are widely dispersed, and even in some species where females do not disperse widely, sperm production may be limiting [12]. Also, sex-biased hunting can cause social disruption through mechanisms such as increased competition for females between remaining males, or an inadequate number of large dominant males to fertilize receptive females [12]. In the sable antelope (Hippotragus niger), an increase in calf mortality was linked to a decrease in calving synchrony, and thus less effective "predator swamping"; the lack of synchrony was caused by too few adult male antelopes [17]. A study of wolves (Canis lupus) showed that heavy hunting pressure decreased the average size of social groups, 
caused mating to be less selective, increased variability in territories and home ranges, and led to higher natural mortality rates (excluding the kills from hunting by humans) [18]. One mechanism identified for the higher mortality was disruption of social groups, leading to the formation of new groups and dispersal of individuals that usually died.

Here, we review exploitation of populations of highly social odontocetes and attempt to assess whether they were depleted and, if so, whether they have shown evidence of recovery after exploitation ceased, or instead not recovered as expected. Additionally, we look for evidence of social and behavioural factors that may have hindered recovery. Finding examples of well-studied populations of odontocetes, where resilience to exploitation has been "tested" and measured in some manner is not easy. Even "precipitous declines" in marine mammal populations can be hard to detect using presently available methods [19]. In the case of cetaceans, small, accessible populations are the most easily monitored. This creates the potential for a serious bias because such populations may not be representative and may even be anomalous. Nonetheless, we attempt to review all known cases of exploitation of highly social odontocetes where data are available and discuss aspects of their social structure and behaviour that may affect their resilience to exploitation. Importantly, this means that we do not focus on porpoises, whose lack of resilience to exploitation, evident in multiple regions, appears to be explained primarily by their life history.

We reemphasize that the life history of odontocetes, which prevents their populations from growing quickly, is likely the primary reason for their apparent lack of resilience to heavy exploitation. What we consider here is whether social and behavioural traits of odontocetes (not seen in mysticetes) contribute further to this observed lack of resilience. After our review of these traits, we also consider alternative contributing factors, primarily the higher levels of contaminants in odontocetes relative to mysticetes, the higher levels of bycatch often seen in populations of small odontocetes, and the competition often inferred between odontocete populations and commercial fisheries for the same prey (something not usually seen in mysticetes, which generally feed at lower trophic levels that are not commercially exploited). It is likely that multiple factors often act in concert to inhibit recovery of odontocete populations, and our objective here is to increase awareness and consideration of the possible role of social and behavioural traits.

\section{Sperm Whale, Physeter macrocephalus}

Sperm whales have been likened to elephants in their social organization, life history, and vulnerability to exploitation. It has been suggested that large size, wide range, and temporally extensive communal memory help both sperm whales and elephants "ride out considerable temporal fluctuations in their food supply" [20, p. 169]. Furthermore, female reproductive output declines with age in both sperm whales and elephants, and in elephants, and perhaps also in sperm whales, old females ("matriarchs") function as herd leaders and as "reservoirs of ecological knowledge" [21, p. 279]. As mentioned previously, the selective killing of elephant matriarchs for their large tusks may reduce the "social knowledge" available to a group or herd [11]. Although it is difficult to quantify, or even to prove the existence of, this function in sperm whale society, there is some circumstantial evidence for it. In warm El Niño years when foraging conditions deteriorate around the Galápagos Islands (Ecuador), groups of females and young sperm whales move "fast and straight" to areas as much as $1000 \mathrm{~km}$ away, presumably "where an older female remembers fair feeding during previous Niños" [21, p. 285]. The downside is that the loss of old individuals due to hunting or "cropping," on the assumption that they are surplus or expendable, could mean the loss of valuable cultural capital in the sperm whale group. A recent study showed that different sperm whale social groups have different foraging success under different climatic conditions, with some doing better during El Niño events [22]. Thus, social groups may differ in their ability to adapt to changing environmental conditions. The implications of lost wisdom are hard to discern and may vary greatly, depending on chance events and circumstances-if all goes well, the group may persist long enough to regain or replace the lost knowledge, it may merge with another group that still has plenty of cultural capital, veterans may join it, and so forth.

Sperm whale social groups appear to be formed by temporary associations between smaller, more stable social units, therefore creating a mix of clusters of closely related individuals and others with no close relations [23]. Calf protection is thought to be an important function of sociality among female sperm whales because adults make long feeding dives to depths where calves cannot follow; nonsynchronous diving patterns ensure that adult females are often at the surface with calves and perform a "babysitting" role to protect calves from predation by killer whales or other predators [24]. In general, allomaternal care makes individuals dependent on one another for communal care of young, which promotes sociality [23]. Whaling could disrupt the social relations and social structure of sperm whale groups and, in turn, affect survival of sperm whale calves and juveniles.

Using the population of sperm whales around the Galápagos Islands as a case study, Whitehead et al. [25] argued that exploitation can continue to have substantial negative effects on the size and recruitment rate of a population for at least a decade after the exploitation has ended. In a long-term photoidentification study, they documented a decrease in sperm whale abundance around the Galápagos of about $20 \%$ per year (95\% CI: 7 to $32 \%$ ) between $1985-$ 1995. In the absence of any evidence of substantial mortality or health problems, and given some direct evidence of emigration by individual female sperm whales to mainland Ecuador, northern Peru, and the Gulf of Panama, those authors concluded that the marked decline in the Galápagos was principally due to emigration. However, they also found a remarkably low reproductive rate in the Galápagos whales, about 0.05 calves/female/year. With so little recruitment, the population would be, at best, barely sustainable even if there 
were no emigration. To explain their results, Whitehead et al. pointed to an intense period of modern whaling in Peru from 1958-1981, when virtually the entire local population of large male sperm whales ( $>13.5 \mathrm{~m}$ ) had been wiped out [26]. This whaling, they reasoned, was affecting the sperm whales in their Galápagos study area in two main ways. Firstly, it reduced the density of sperm whales in the productive Peru Current system, "leaving both good feeding for animals entering these waters and providing little incentive to leave, effectively resulting in one-way migrations" [25, p. 1394]. Secondly, by drastically depleting large males in the region, it led to very low pregnancy rates, which persisted "for many years." The point here is that if there were a strong female preference for large males, a lack of "suitable" males would lead to lower pregnancy rates even though younger and smaller males still exist in the population (see above regarding examples in terrestrial mammals). Mate selection by females is generally ignored or discounted in most population models, where it is assumed that any number of reproductive-aged males will successfully impregnate all reproductive-aged females that are ovulating. Ginsberg and Milner-Gulland [12] describe scenarios in ungulates, where a sex-biased hunt leading to decreased fecundity can lead to population collapse.

Determining whether sperm whales have recovered from exploitation is difficult. In a worldwide review, no evidence was found to suggest that any population of sperm whales had increased significantly [27], but few areas with trend data were available. In California, one of those few areas, the sperm whale population was relatively stable from 1979 to 1991 [28]. On a global scale, Whitehead [29] used three methods for scaling up available abundance estimates to produce a worldwide estimate, and these resulted in a consistent total of about $360,000(\mathrm{CV}=0.36)$ sperm whales. A back-calculation model using catch records suggested that pre-whaling numbers were about 1,110,000 (95\% CI: $672,000$ to $1,512,000)$, and that the population was about $71 \%$ (95\% CI: 52 to $100 \%)$ of its original level in 1880 as open-boat whaling drew to a close and about 32\% (95\% CI: 19 to $62 \%$ ) of its original level in 1999, 10 years after the end of large-scale industrial whaling [29]. Recent estimates of sperm whale density have been much higher in the western North Atlantic than in other parts of the world [29], suggesting there may have been recovery in this region. This could be due to the fact that although the North Atlantic population was subject to open-boat (nonmechanised) whaling throughout most of the 18th and 19th centuries and, at least locally (e.g., the Azores and Madeira; see [30]), during much of the 20th century, it was largely spared from large-scale, modern, factory-ship whaling which was concentrated in the southern oceans and North Pacific throughout the first three-quarters of the 20th century. Maximum potential rates of increase are thought to be quite low in sperm whales. A value of $0.9 \%$ has been suggested by the Scientific Committee of the International Whaling Commission [31] for a population with a stable age distribution. Whitehead [29] used a mortality schedule from killer whales combined with pregnancy rate data from sperm whales to estimate a maximum rate of increase of $1.1 \%$, with a "reasonable range" of 0.7 to $1.5 \%$, suggesting that sperm whale populations would be vulnerable (i.e., nonresilient) to relatively modest exploitation rates.

\section{Beluga or White Whale, Delphinapterus leucas}

Belugas are highly social odontocetes that are commonly found in groups of 2-10 and often aggregate in assemblages of up to hundreds or possibly thousands [32]. There is limited evidence that the basic social units of groups are matrilines, consisting of adult nursing females accompanied by older female offspring [33]. These "triads" may sometimes join to form large nursery groups [32]. Separate pods of adult males are sometimes observed. There is also some evidence that males migrate separately from or feed apart from females, calves, and immatures. It is not clear whether belugas form stable social groups beyond those of the immediate matrilines. However, their substantial vocal repertoire and observed behaviour (e.g., closely spaced grouping and susceptibility to "driving" by hunters) indicate a high degree of sociality in this species, even though their social system is not completely understood or described. Many populations of belugas make large seasonal movements in relation to prey availability and ice conditions, suggesting that cultural retention of knowledge of movement patterns could be important. Avoidance of ice entrapment, for example, is a risk that may be lessened by experience and knowledge of older individuals in groups.

Through the 1970s, it was generally believed that belugas could be exploited sustainably by removing on the order of 0.05 to 0.10 of a given population annually [34]. With larger samples of biological material and better analytical techniques, it came to be widely accepted that $r_{\max }$ for belugas (and, incidentally, narwhals, Monodon monoceros) is well below 0.10. Sergeant [35] reasoned that an offtake rate of 0.05 was "probably sustainable" for monodontids as long as the hunting was selective for males and especially adult males. Kingsley [36], using a simple model of population dynamics, suggested that 0.03-0.04 was a more realistic range of "permissible exploitation rates" for these species. Such rates are generally used to assist in the management of hunts that can be highly stochastic. In their formulation, they do not explicitly incorporate consideration of social, behavioural, or cultural factors.

Belugas have been heavily exploited in much of their range, often over timescales of hundreds of years. In at least two areas, southwestern Greenland and southern Ungava Bay (eastern Canada), they were essentially extirpated by commercial whaling $[37,38]$. In both of those cases, the mode of capture extended beyond the single hunter in a kayak or canoe armed with a harpoon or rifle, to include drive and net hunts in which tens or hundreds of whales could be taken at a time. Although similar hunting techniques were practiced in many other areas (e.g., Svalbard, eastern Hudson Bay, Cumberland Sound, Prince Regent Inlet, central-western Greenland, and the Okhotsk, Kara, White and Barents seas 
[39]) at least relict numbers of belugas survived so that the populations in those areas are still extant.

Trends in beluga populations have been monitored intensively in two areas: the St. Lawrence River in Canada and Cook Inlet in Alaska. In both areas, hunting (along with weir trapping in the St. Lawrence) reduced the populations to less than a third of prehunting levels [40-43]. In the St. Lawrence, belugas have been completely protected from direct exploitation since the late 1970s, but the question of whether any recovery has occurred is unresolved despite careful population monitoring since then [43]. Similarly, the closure of hunting for Cook Inlet belugas in the early 2000s has not resulted in any measurable recovery by that population [44]. Several other areas where large beluga populations were greatly depleted by hunting, for example, central-western Greenland, eastern Hudson Bay and Cumberland Sound, have been monitored periodically, and there is no clear evidence of sustained recovery by any of those populations. Importantly, none of the once-large beluga populations in northern Russia has been monitored rigorously for trends following decades of intensive exploitation under the Soviet regime.

We are aware of only one example where there is direct evidence for a beluga population increase. The results of aerial surveys of inner Bristol Bay (Alaska) between 1993 and 2005 have been interpreted as suggesting that the local population of belugas increased during that period at a rate of nearly $5 \%$ per year [45]. In this instance, however, there was no history of intensive exploitation, no tradition of using drive or net techniques leading to mass removals, and no reason to believe the population had been seriously depleted prior to 1993.

Social systems of belugas are not well understood, partly due to the lack of individual-based studies, such as the long-term photoidentification studies of sperm whales, killer whales, and bottlenose dolphins (Tursiops spp). Therefore, we have little direct evidence that exploitation has caused disruption of beluga societies in ways that would lead to population consequences. However, there are at least five and perhaps as many as seven areas where belugas have failed to show any sign of recovery following exploitation: southwestern Greenland, southern Ungava Bay, Cook Inlet, the St. Lawrence River, and eastern Hudson Bay, possibly also Cumberland Sound and central-western Greenland. Although there is a good reason to believe that continued direct removals by hunting are partly responsible for the lack of recovery in some of those areas, we suggest that the disruption of beluga behaviour and social systems is a contributing factor.

\section{Narwhal, Monodon monoceros}

Even less is known about the social system of the narwhal, a close relative of the beluga. The pronounced sexual dimorphism of narwhals, most obvious in that usually only males have tusks, along with observations of "sparring" by males and heavy scarring on the melons of adult males, together implies a mating system where males physically compete for dominance or access to mating opportunities [46]. This suggests a mating system where relatively few males mate successfully.

Narwhals have been hunted intensively by northern people in Canada and Greenland for centuries. In Greenland, the hunt became subject to annual catch limits only as recently as 2005, and in Canada narwhal hunting has been managed in recent decades largely at the community level and through federal land-claims agreements [47]. The number of narwhals in northwestern Greenland was estimated to have declined between 1985-86 and 2001-02 at a rate of $6 \%$ per year [48], and Heide-Jørgensen and Acquarone [49] expressed concern that narwhal abundance had also declined off western Greenland. In both cases, overexploitation was suspected as the cause, or at least as a contributing causal factor. More recent surveys of narwhals in Greenland waters resulted in higher abundance estimates and therefore called into question the earlier indications of declines [50].

It is likely that in areas of heavy exploitation, not only the numbers but also the social structure of narwhals have been affected by the hunting. Hunters in some areas and at some times select individuals with large, commercially valuable tusks [51]. As was mentioned above, this type of trophy hunting, with selective removal of alpha adult males, has been shown in bighorn sheep to lead to decreased reproductive success [15]. Besides the potentially disruptive effects on reproduction, removals of older individuals may have some of the same insidious effects on narwhal populations that we suspect they have on belugas. For example, although warming trends in the Arctic have generally caused sea ice to shrink in extent and thickness, ice coverage has been increasing over the last several decades in Baffin Bay, one of the narwhal's main wintering areas, increasing the risk of ice entrapment [52]. Laidre et al. [53] suggest a recent increasing trend in large entrapments of narwhals in summer. As was suggested for belugas, this risk may be lessened by availability of the experience and knowledge of older individuals in groups.

\section{Killer Whales cf. Orcinus orca}

Killer whales have a life history that is similar to that of humans, as they reach sexual maturity in their teens, females reach reproductive senescence in their 40 s, and some individuals are thought to live to 80 years or older [54]. Various types of killer whales have been described, differing in their morphology, genetics, and foraging specialization (e.g., $[55,56])$, but all killer whales that have been studied appear to live in relatively stable social units. In many or most populations, these stable social units are matrilineal, and often exist over long periods of time. The extreme is seen in North Pacific "resident-type" (fish-eating) whales, where matrilineal social groups appear to be permanent, meaning offspring never or very rarely disperse from their mother's group [56,57]. For most or all populations, these stable social units have long-term associations with other such units. In resident-type killer whales in the eastern North Pacific, lineages of vocally and matrilineally related social groups 
appear to form acoustic "clans," which are maintained by vocal traditions [58], giving a social hierarchy of matrilines, pods (collections of matrilines that frequently associate), and clans (collections of pods that are genetically related and acoustically similar).

It has been suggested that some killer whales exhibit evidence of culture, such as foraging specializations between sympatric fish-eating and mammal-eating populations as well as group-specific call dialects that are used by matrilines to stay in contact [59]. Killer whales in different parts of the world have unique foraging techniques that are apparently learned, including hunting of pinnipeds on beaches by intentional stranding [60] and "carousel feeding" techniques used by whales in Norway to herd and prey on herring (Clupea harengus) schools [59]. In many populations there are examples of substantial seasonal movements in search of prey, such as movements following herring out of fjords in Norway into the Atlantic Ocean. These characteristics make killer whales, like the other species described above, potentially vulnerable to social disruption and the loss of cultural and ecological knowledge through removal of older individuals.

Two populations of resident-type killer whales in the northeastern Pacific were exploited in the 1960s and early 1970 s by live-capture removals for the aquarium industry, and by intentional shooting by fishermen who perceived them as competitors [61]. As mentioned earlier, residenttype killer whales live in a social structure of long-term associations of matrilines. This suggests that the cultural capital retained by older individuals (both female and male) in the matriline is of considerable importance, and therefore the removal of such individuals would have a disproportionately large effect on the population's ability to adapt and flourish.

The southern resident population is estimated to have declined from a population size of $\sim 140$ or greater when live-captures began, to only 71 in the mid 1970s when such removals stopped following passage of the US Marine Mammal Protection Act [62]. The population has shown some signs of recovery but has fluctuated over the last few decades between $\sim 80-100$. This variability has been driven by fluctuations in survival rates that are correlated with Chinook salmon (Oncorhynchus tshawytscha) at-sea abundance indices [63]. The direct removals may have caused substantial disruption to the social structure of the population, so this is a plausible hypothesis to explain, at least partially, the lack of recovery. However, there are other competing hypotheses, particularly that recovery has been hampered by human-caused declines of Chinook and other species of salmon, or by the high levels of persistent organic pollutants (POPs) in their fat stores [64-66]. There could be an interaction between these two factors, where a lack of prey in some years leads to utilization of fat stores that remobilize sequestered POPs into the bloodstream, perhaps to levels capable of causing reproductive problems and immune suppression [62]. Southern resident killer whales make substantial seasonal movements: one group (J pod) moves into southern Puget Sound in autumn in pursuit of chum salmon (Oncorhynchus keta) runs, while two other groups ( $\mathrm{K}$ and $\mathrm{L}$ pods) move from Washington to Oregon and California in winter, apparently in pursuit of Chinook salmon, and these whales also move as far north as the Queen Charlotte Islands [67]. According to contaminant ratios, L and K pods have a partially "California signature," whereas J pod does not $[65,66]$. Given that these whales apparently undertake long-range movements intended to intercept specific salmon runs at specific times and places, and that salmon runs themselves undergo substantial interannual fluctuations tied to oceanic regime shifts, killer whales must adapt their movement patterns to existing conditions in different years. Therefore, the population may benefit greatly from knowledge of older individuals that have experienced a broad range of ocean conditions. Different matrilines may have different cultural knowledge that could be more or less helpful as ocean conditions change, as mentioned above for sperm whales.

The northern resident population was also exploited by live-capture removals and intentional shooting, but was likely not depleted to the same degree as the southern resident population. The northern resident population increased at a rate of $2.6 \%$ in the 1970 s, 1980s, and early 1990s [68] and has been roughly stable since then. The southern-most pods of the northern resident population have experienced fluctuations similar in scale to those of the southern resident population, which is interesting as these are the pods that live in closest proximity to the southern resident population and may share its food supply [63]. Survival rates in the northern resident population have also been correlated with salmon abundance [63], and northern residents also have high levels of POPs, so the same confounding factors apply to this population when it comes to explaining the lack of sustained recovery.

Individuals from both resident and "transient"-type (mammal-eating) populations of killer whales in Alaska apparently died from exposure to oil in the Exxon Valdez spill and suffered losses of $33 \%$ and $41 \%$, respectively, in the year following the event [69]. Additionally, resident-type whales were shot by commercial fishermen defending their catches prior to regulations outlawing such shooting in 1986. Sixteen years after the spill, the AB pod from the residenttype population had not recovered to pre-spill numbers, and its rate of increase was significantly lower than other pods that did not decline after the spill (1.6\% per year versus 3.2\% per year). The slowness of the AB pod's recovery is attributed largely to the loss of juvenile and young adult females, which resulted in a significantly lower birth rate than observed in other pods [69]. Also, an apparent change in social structure was observed after the spill as one subpod changed its pattern of association with other subpods, the only such change documented in more than 20 years of monitoring [69]. A potential mechanism for this type of change can be seen in the study by Lusseau and Newman [70], who inferred from association data that a few key individuals provide the connections among subgroups to maintain social cohesion within a small population of bottlenose dolphins, and in a similar simulation study of northern resident killer whales [71]. The transient-type AT1 population of killer whales was already heavily skewed towards adult males prior to 
the Exxon Valdez spill and apparently had a low reproductive rate, but the deaths of nine whales (seven of juvenile or reproductive age) immediately after the spill likely did not help. The population has not produced a calf in over 20 years and is likely to go extinct within the next several decades. Additional causes of its failure to recover, besides the demographic problems, may include high POP levels [72] and a sharp regional decline in harbour seals (Phoca vitulina) [73], the primary prey of AT1 killer whales.

These examples suggest that killer whale populations are not very resilient to exploitation. This may be solely or primarily due to their life history, as was suggested for the $A B$ pod by Matkin et al. [69], who cited a low birth rate caused by a shortage of reproductive-age females due to removals as the main hindrance to recovery in that case. On the other hand, the lack of sustained recovery of southern resident killer whales could be partially due to social disruption and the loss of cultural capital. Specifically, the whales may find it harder to find alternative prey when their primary salmon prey are at low availability, for example, in winter months when certain types of prey are not as highly concentrated as they are at other times [63]. However, depletion of many of their prey fish populations by overfishing or habitat degradation confounds any interpretation of the root cause of this population's failure to recover.

Williams and Lusseau [71] showed from data on northern resident killer whales that particular individuals were more important than others to maintaining the social network throughout the population. When those authors simulated the removal of individuals of the same age and sex, as the live-capture industry had done, there was a greater probability of fragmentation of the social network connecting the entire population. They interpreted their results as suggesting that anthropogenic removals targeting particular matrilines implicitly and particular age or sex classes explicitly could have different population-level effects than random culling.

\section{Pilot Whales, Globicephala spp.}

Pilot whales are highly social and are usually found in large schools averaging 20-90 individuals, and their social structure is thought to be similar to that of killer whales [74]. Long-finned pilot whales (Globicephala melas) appear to live in permanent matrilineal social groups where offspring do not disperse from their natal group, and males are thought to mate outside of their group [75]; less is known about short-finned pilot whales (Globicephala macrorhynchus), but they also appear to live in long-term social groups. In both species, older adult females apparently have a role other than solely reproduction; short-finned pilot whales show evidence of complete female reproductive senescence [76], and long-finned pilot whales show a decline in fecundity with age but not a complete cessation of reproduction [77]. It has been suggested that the death of an older mother could substantially reduce the survival probabilities of several dependent young and perhaps other close relatives [78]. Cooperative foraging and food provisioning have been suggested as benefits that postreproductive females could give to stable social groups [79], and this is supported by evidence of lactation in females that are no longer reproductively active (also true of sperm whales). Norris and Pryor [80] suggested that postreproductive females in pilot whale schools could also be repositories of cultural information, such as the whereabouts of feeding grounds.

Long-finned pilot whales have been hunted in the Faroe Islands since at least the 10th century. The strong social bonds of pilot whale schools allow an entire school to be herded and driven ashore (or at least into coastal shallows) and killed. Catches in the Faroese drive fishery have averaged $\sim 1000$ whales per year for the last 300 years, which indicates that the level of removal is sustainable. Studies have found significant differences in pollutant concentrations $[81,82]$ and parasite burdens [83] between schools of pilot whales landed on the Faroe Islands at different times and locations. This means that the schools spend different proportions of their time in different areas, which makes it possible that there is more than one stock of long-finned pilot whales in the North Atlantic, and in fact more than one stock subject to hunting in the Faroe Islands. Systematic surveys in the North Atlantic were conducted in 1987 and 1989, and abundance of long-finned pilot whales in Faroese survey blocks in 1987 (a year with more survey effort around the Faroe Islands) was $64,779(\mathrm{CV}=0.454)$ [84]; a catch of 1000 whales per year represents $\sim 1.5 \%$ of that abundance estimate. The most extensive survey of the North Atlantic was completed in 1989, with a total abundance estimate of $778,000(\mathrm{CV}=0.295)$ [84]. Summing abundance over only survey blocks in the eastern half of the survey area (blocks 10, 20, 36, 40, 50, and 88 ) results in a total of 421,000 ; a catch of 1000 whales per year represents $\sim 0.2 \%$ of that abundance estimate. It remains unclear exactly what abundance the Faroe Islands catch should be compared to, but the evidence that multiple stocks (or at least whales from multiple regions) are taken suggests a broader area than just the immediate waters around the Faroe Islands. If this is the case, the catch may have been sustainable because the population(s) from which it is taken is (are) large enough to support that removal (which would probably represent less than $1 \%$ of the population size).

Another potential factor is the nature of the hunt, which is a drive fishery that kills entire schools or aggregations of pilot whales found together. This would result in the least amount of social disruption to the remaining whales (as compared to removing a small percentage of individuals from many different social groups each year). There is no way to determine whether this has been an important factor in the sustainability of this hunt, but it is a plausible, or at least interesting, hypothesis. An alternative interpretation would be that matriline-based knowledge or foraging specializations become lost during a hunt where a whole matriline is completely removed [71]. In essence, this is how Whitehead and Rendell [22] interpreted the differential foraging success of sperm whale matrilines during El Niño events.

Long-finned pilot whales were also subject to a drive fishery in Newfoundland from 1947 to 1972, and this fishery apparently reduced the stock to very low levels [85-87]. It also frequently took entire social groups [88] in a fashion 
similar to that of the Faroe Islands drive fishery. Abundance at the onset of the fishery was estimated to be about 60,000 animals from an analysis using the catch record and data from the squid fishery [85]. Hay [86] conducted an aerial survey in 1980 in eastern Newfoundland and Labrador waters, and estimated 13,167 whales (95\% CI: 6731 to 19,602 , not corrected for diving whales or whales missed by observers). During the height of the fishery from 1951-1960, an average of $\sim 4000$ whales were killed per year; this declined in the next decade (1961-1970) to an average of $\sim 1300$ per year, with the drive fishery apparently collapsing after 1967 [85]. Thirteen hundred is $\sim 10 \%$ of the survey abundance of 13,167 , and 4000 is $\sim 7 \%$ of the 60,000 preexploitation size estimated by Mercer [85], so this population appears to have been overexploited. Nelson and Lien [87] concluded the population had not yet recovered given the relatively low abundance estimated by Hay [86] and others, and the lack of recovery was speculated to be due to a relatively low rate of population increase and insufficient passage of time.

Short-finned pilot whales are killed in Japan in drive fisheries, crossbow fisheries, and small-type whaling, but they have not been the main targets of any of these hunts [89]. There has been a moderate decline in total catches over time $[89,90]$. An average of 246 whales were taken per year from 1995 to 2004, well below the quota of 450. It is not clear if the decline in catches and the failure to reach the quota should be interpreted as a decline in the population. Recent catches averaged $\sim 1.2 \%$ of estimated pilot whale abundance, while earlier catches averaged $\sim 1.8 \%$ of abundance [90], but interpretation of these values is problematic due to the uncertainties about population structure.

Pilot whales of both species are among the cetaceans most frequently involved in mass strandings in which the entire group dies. Although a number of hypotheses have been proposed for the cause of these mass strandings, the one thing that is certain is that strong social bonds exist within pilot whale schools [74]. This may make pilot whales particularly vulnerable to the removal of certain individuals from social groups.

\section{Eastern Tropical Pacific Dolphin Populations}

Tropical and temperate-region oceanic dolphins are thought to live in fission-fusion societies, where small social units (such as mother/calf pairs) aggregate in schools of hundreds or even thousands of individuals. The composition of these schools can change rapidly from day to day as the school splits or joins other schools. Beyond the obvious social unit of mother/calf pairs, other longer-term social associations, such as juvenile subgroups and adult male alliances, have been described in several closely related and well-studied (coastal or island-associated) odontocetes such as bottlenose dolphins [91-93] and spinner dolphins [94].

Dolphins of several species are incidentally killed during tuna purse-seine fishing in the eastern tropical Pacific (ETP). Fishermen use the dolphins to locate schools of tuna, and chase and encircle the dolphins in nets to facilitate the catch of tuna that swim below [95-97]. Over the period 1960 to
1972, more than 4 million dolphins were killed by purseseine vessels fishing for yellowfin tuna (Thunnus albacares) in the ETP [98]. At least two dolphin populationsnortheastern offshore pantropical spotted dolphins S. attenuata attenuata and eastern spinner dolphins S. longirostris orientalis - are estimated to have been reduced to $40 \%$ and $20 \%$ of their pre-exploitation levels, respectively, because of high mortality from purse seining during the 1960s and early 1970s [99].

Although spotted and spinner dolphins in the ETP do not appear to live in long-term stable social groups, they do show signs of a relatively complex social structure. The proximity of individuals in aerial photographs of spotted dolphins suggests subgroups of 2 to 8 individuals within large schools [100]. Observations of spotted dolphins captured in purse seines suggest a variety of types of subgroups within schools, including groups of females with their young, triads (two adult females and a calf), groups of juveniles, and groups of adult males [100]. At a larger scale, two types of schools have been observed in the ETP. The first type is the breeding school, often numbering a few hundred animals, that contains more females with young and fewer juveniles than expected from a stable age distribution. The second type is often smaller and consists of mostly male or mostly juvenile dolphins [100]. These schools can themselves temporarily fuse into even larger aggregations.

In a recent assessment of trends in dolphin populations in the ETP, Gerrodette and Forcada [101] concluded that, despite reductions in fishing mortality spanning two orders of magnitude, neither the population of northeastern offshore spotted dolphins nor that of eastern spinner dolphins had increased in abundance by the year 2000. Thus, neither stock was considered to be recovering, even though reported kills in the fishery had been reduced from a high of hundreds of thousands per year to fewer than 1000 per year, which represented much less than $1 \%$ of the best estimate of population size. Wade et al. [99] estimated that both populations remained depleted. They compared models intended to be indicative of hypotheses to explain why neither dolphin stock had recovered, with results giving equal support to those attributing to the lack of recovery to effects of the fishery and those attributing it to changes in the ecosystem. Their conclusion was that the purse-seine fishery could well be affecting the dolphin populations in other ways than simply removal of relatively small numbers of individuals as bycatch, but that the degree to which cryptic effects are having population-level consequences is unknown.

Despite the major reduction in dolphin kills, the number of intentional sets on dolphins has not declined; the decline in kills has occurred primarily because of a major decline in the number of dolphins killed per set, which is due, in turn, to increased effort by the fishermen to release the dolphins. The number of dolphins chased, captured, and released during fishing operations is high [102], and individual northeastern offshore spotted dolphins interact with the fishery between 2 and 50 times per year, depending on size of the school [103]. This rate of interaction likely has negative effects on survival and/or reproduction through 
increased energetic demands from chase, elevated stress from chase and encirclement [97, 104], and increased predation risk on release from encirclement [105].

Behavioural changes in swimming and schooling dynamics occur during the tuna-fishing process. Separation of individuals in a group can occur during the chase (due to different swimming speeds or splitting into subgroups during evasive manoeuvres), during encirclement (due to individuals ending up inside or outside the net), and during release (due to confusion and flight responses as the dolphins are slowly released from the net). Perhaps the most dramatic separation occurs between mothers and calves [102]. Estimated long-term sustainable speed is about $1 \mathrm{~m} / \mathrm{s}$ for neonates compared to about $2.5 \mathrm{~m} / \mathrm{s}$ for adults, and power estimates for 2-year-old spotted dolphin calves are about $40 \%$ higher than power estimates for adults needed to maintain the same speed [106]. Under normal circumstances, these higher demands are generally offset by calves drafting their mothers and using other energysaving strategies, but the relatively high speeds associated with flight and evasion during and after tuna sets likely make this more difficult. Noren and Edwards [107] suggest that evasive behaviour of mothers during chase, coupled with the developmental state of calves, provides a plausible mechanism for mother-calf separations and subsequent mortality of calves, and that the potential for separation is highest for dolphins in their first year, becoming progressively lower with age as immature dolphins approach adult stamina levels and attain independence. Archer et al. [102] found a deficit of calves relative to the number of lactating females killed in $24 \%-32 \%$ of spotted-dolphin sets and in $13 \%-$ $19 \%$ of spinner-dolphin sets examined. Archer et al. [108] extended this analysis over a longer time series and estimated that from $75 \%$ to $95 \%$ of the lactating females killed were unaccompanied by a calf, and it is assumed that their orphaned calves would not survive without their mothers. Over the time series, total kill was estimated to be $14 \%$ higher per year when missing calves were taken into account.

Exploitation may also have an effect on spinner dolphins through disruption of their mating system. Differences in testes size indicate that eastern spinner dolphins have a more structured polygynous mating system than other subspecies of spinner dolphins; relatively few adult eastern spinner males participate in mating. Perrin and Mesnick [109] found that only 4 out of $699(0.6 \%)$ eastern spinner males examined had testes plus epididymides weighing more than 700 grams, the level at which all epididymides contained sperm. They interpreted this finding to indicate that only this tiny fraction of the male population was capable of successful mating. This could mean that eastern spinner dolphins are exceptionally vulnerable to perturbations caused by chase and capture in the tuna purse seine fishery, for example, breaking up schools and disrupting social bonds by altering the spatial distribution of animals within schools [109]. If few males participate in mating, the removal of important individuals could suppress reproduction. Calf production has been declining since at least 1987 for both eastern spinner and northeastern offshore spotted dolphins [110], suggesting that some aspect of interaction with the fishery could be the cause.
Given these different lines of evidence, various authors have concluded that it is plausible that the chase and encirclement of dolphin schools by the fishery has hindered or perhaps completely prevented recovery of the depleted populations [97, 99, 101]. Both populations were estimated to be increasing at less than $1 \%$ per year, a significantly lower rate than expected for dolphins (3-4\% per year). It is likely that other species of social odontocetes would be similarly affected if exposed to decades of repeated harassment and social separation during a hunt that involves a relatively long chase of the group. Although the interaction between the tuna fishery and dolphin populations is an exceptional case, the indirect effects of the chase and encirclement of dolphin schools by the tuna purse-seine fishery may be taken to imply that there are similar effects from other types of direct exploitation of odontocete populations that involve pursuit.

\section{Discussion}

Our review has clearly been limited by the sparseness of data on abundance, trends in abundance, exploitation levels, and population structure as well as by not having a full understanding of social systems in most odontocete species. Nonetheless, the results are thought-provoking. We found little evidence of strong recovery for decades after the phase of intense exploitation had ended in any of the depleted populations examined. There is little evidence for recovery of sperm whale populations except perhaps in the northwestern Atlantic. Belugas have declined in many areas, and in at least five, and perhaps as many as seven, areas they show no signs of significant, sustained recovery. At least three killer whale populations have not recovered as expected, and the same is true of two dolphin populations in the eastern tropical Pacific. Only in pilot whales did we find evidence of a region (Faroe Islands) where substantial exploitation over a long period of time has been sustained; in other regions (e.g., Newfoundland, possibly Japan), pilot whales appear to have been overexploited and their extent of recovery is unknown. We hasten to add that the hunting of belugas and narwhals in some parts of the Arctic has, like the hunting of pilot whales in the Faroes, been sustained over centuries, with the whale populations remaining large and healthy (e.g., Mackenzie Delta, western Hudson Bay, Bristol Bay, and eastern Canadian Arctic), but some populations of these species also have collapsed after hunting escalated to involve commercial ventures in relatively recent times.

The documented recovery of many populations of baleen whales is striking when compared to the lack of evidence for recovery of odontocete populations. Some of the difference is likely due to the relative lack of good monitoring data for odontocetes [19]. Also, in many cases the history of odontocete populations is probably confounded by continued exploitation through bycatch or unreported deliberate removals. Their relatively low population potential rates of increase mean that odontocete populations can be overexploited with take rates of only a few percent per year.

However, in several species of highly social odontocetes there is evidence that exploitation could have effects beyond 
the simple dynamics of individual removals (Table 1(a)). Four species showed evidence of a decrease in birth rates following exploitation, from mechanisms that include a deficit of adult females, a deficit of adult males, and disruption of mating systems dominated by a few individuals. The prolonged dependence of calves in social odontocetes (lactation can last up to four or five years, and a 13-yearold sperm whale with milk traces in its stomach provides an extreme example [111]) increases the risk of mortality from the physical separation, and sometimes orphaning, of calves from their mothers during chasing and harassment from directed hunting or fishing operations. In contrast, calves of baleen whales are generally weaned and fully independent by 6-9 months of age.

Several other mechanisms that could affect recovery of odontocete populations can be predicted from their social systems (Table $1(\mathrm{~b})$ ). In every species reviewed here, it seems plausible that a loss of cultural knowledge of feeding grounds, prey, or foraging techniques could result from the removal of older individuals, perhaps particularly older females in matriarchal societies. The magnitude of this effect could be determined by the rarity of the environmental conditions that challenge a population. Populations may gain the most benefit from the presence of older individuals in years or periods when environmental conditions occur that have not been experienced for a long time. For example, older individuals in a group of narwhals or belugas might help the group avoid ice entrapment, a benefit that would be especially important when entering colder periods in climate cycles.

Beyond the loss of cultural knowledge, there may be other effects from the loss of older individuals. Postreproductive individuals in stable societies might play important roles in recruitment, such as the nursing of calves by postreproductive females ("nannies") suggested in pilot whales. In sperm whales (and other species), the disruption or fragmentation of social groups may compromise protection from predation. Unrelated adults may no longer be available to "babysit" or the group may become too small to physically defend smaller animals from attack by killer whales. More speculative but interesting are other extended ramifications, such as the possible collapse of social networks through the removal of key individuals [70, 71], leading to the formation of new groups and dispersal of individuals, potentially causing higher mortality rates, as observed in wolves under heavy hunting pressure [18].

\section{Confounding Factors and Alternative Hypotheses}

In some, possibly many, cases, the history of a population is confounded by undocumented continued exploitation, understood to include fishery bycatch as well as direct hunting. This could apply equally to mysticetes and odontocetes although it might be argued that the incidental mortality of small odontocetes is more cryptic than the mortality of large, relatively conspicuous mysticetes. The likelihood of documentation also would vary depending on remoteness of the region, the distance from shore, and the relative intensity of monitoring effort. In particular, entanglement of small odontocetes in set-gill-net and drift-net fisheries is an issue of widespread conservation significance [112, 113]. In many areas, where monitored, bycatch in fisheries exceeds sustainable limits for dolphins, porpoises, and small whales, but many if not most regions of the world lack adequate monitoring [114]. The lack of recovery for many populations of odontocetes may be due, at least in part, to ongoing bycatch.

There are other alternative hypotheses to explain an apparent failure of an odontocete population to recover from overexploitation. For example, tissue concentrations of persistent organic pollutants (POPs) differ markedly, on average, between the mysticetes and the odontocetes [115], with mysticetes carrying much lower burdens consistent with feeding at lower trophic levels. In contrast, some odontocetes, such as killer whales, are found to have some of the highest burdens measured in any cetacean [65]. Indeed, a lack of recovery by St. Lawrence River belugas has been partly attributed to POPs in combination with observations of disease-associated deaths [116]. Moreover, odontocetes often compete for prey with fisheries. In general, odontocetes rely on fishes, elasmobranchs, crustaceans, and cephalopods as prey, whereas some mysticetes (e.g., balaenids and blue whales) are obligate planktivores and others (e.g., sei (Balaenoptera borealis), fin (Balaenoptera physalus), and Bryde's (Balaenoptera edeni), and humpback whales) prey on a mix of zooplankton and nekton. This could mean that differences in resilience to exploitation are at least partly driven by exploitation competition for prey resources [117], with odontocetes more typically engaged in such competition with fisheries (e.g., [118]). In the case of resident killer whales along the west coast of North America, prey populations of salmonids are greatly reduced from preexploitation levels [62], and killer whale survival rates have been correlated with indices of Chinook salmon abundance [63], so the lack of sustained or full recovery by resident killer whale populations may be related more to this factor than to social disruption. On the other hand, the combination of a naturally low reproductive rate, a reduced food supply, social disruption from removal of key individuals, and high levels of contaminants may be a potent combination that has a greater cumulative effect than any single component.

\section{Conclusions}

We are the first to admit that the data summarised in this paper are only suggestive and that firm conclusions linking social and behavioural factors to nonrecovery or compromised recovery of odontocete populations would be premature. We cannot say with certainty that populations of social odontocetes are less resilient to exploitation than populations of mysticetes due solely or mainly to social and behavioural factors. We have, however, sought to summarise the available information in a way that allows such a hypothesis to be articulated with greater clarity so that both scientists and managers can consider its merits and 
TABle 1: Possible mechanisms by which direct exploitation affects odontocete cetaceans, beyond the simple effect on population dynamics of removing individual animals.

(a) Mechanisms for which there is some evidence

Deficit of reproductive-age females (killer whales)

Deficit of adult males leading to lower pregnancy rate in females (sperm whales)

Lowered birth rate from disruption of mating systems (spinner and pantropical spotted dolphins)

Physical separation of cow/calf pairs from chase and encirclement leading to death of calves (spinner and spotted dolphins)

(b) Additional mechanisms suggested by the species' social systems

Loss of cultural knowledge concerning, for example, types of alternative prey, areas where prey can be found, and ways to capture different types of prey under varying circumstances (killer whales, sperm whales, belugas, narwhals, and pilot whales)

Increased risk of ice entrapment due to loss of cultural knowledge (belugas and narwhals)

Disruption of social networks by removal of key individuals leading to dispersal and potentially higher mortality rates (bottlenose dolphins and killer whales)

Loss of an important nonreproductive role played by older females (pilot whales, killer whales, and sperm whales)

Increased predation risk due to loss of social connection and "babysitting" by nonrelatives (sperm whales)

perhaps even "test" it. Further, we have established that, regardless of the cause, there are few examples of populations of social odontocetes that have sustained or recovered from intensive exploitation, and this stands in stark contrast to the documented recoveries of numerous heavily exploited mysticete populations.

We have made no attempt here to discuss the other highly social species of odontocetes for which there are even fewer data. By analogy with the species we have considered, however, we predict that at least some additional species would be vulnerable to the same kinds of effects. For example, the social systems of killer whales and pilot whales are likely similar in some ways to those of false killer whales (Pseudorca crassidens), pygmy killer whales (Feresa attenuata), melon-headed whales (Peponocephala electra), and Risso's dolphins (Grampus griseus). Similarly, the effects of exploitation discussed for spotted and spinner dolphins may apply to other dolphins as well.

Most management of the exploitation of wildlife populations focuses on numbers and on the evaluation of catch levels relative to the population dynamics of the exploited species. Other aspects of the species' biology are not entirely ignored-for example, spawning aggregations of fish may be fully protected, and hunting may be prohibited during the mating seasons of terrestrial mammals. For the most part, however, behaviour and social systems, per se, are rarely considered in determining how (or if) a wildlife population is to be exploited. There have been many calls in recent years for a change from single-species management to ecosystembased management where, at a minimum, the ecological consequences of exploitation by humans are considered explicitly. We suggest that a similar shift in thinking may be warranted for managing the exploitation of highly social mammals, such that explicit consideration is given to the consequences of disruption of social systems and behaviour.

This review leaves managers faced with a conundrum. On one hand, in the absence of widespread direct evidence that social and behavioural traits make odontocetes more vulnerable to exploitation, it could be argued that there is no justification or basis for attempting to incorporate consideration of these traits in the management of odontocete exploitation. On the other hand, the evidence for a lack of recovery by many exploited odontocete species and populations suggests that the exploitation has been poorly managed, and that future management should be more precautionary, whatever the reason might be for the apparent nonresilience of these animals.

Our review suggests a number of plausible mechanisms to explain why social and behavioural traits would cause odontocetes to be less resilient than mysticetes to exploitation. In light of those mechanisms, we believe it would be prudent for managers to consider these traits. As a start, rather than just setting a quota or a maximum allowable take level, more consideration should be given to how the animals are removed from the population, and a goal should be to minimize social disruption. For example, it may be preferable for a hunt to take an entire social group, rather than spread the same number of removals across many social groups, particularly when the hunt itself is highly disruptive of the animals' normal behaviour and activities. Further, it may be necessary to reduce the absolute number of removals to account for the indirect effects of hunts on social mammals, though how to do this in a quantitatively rigorous way is unclear given the lack of good empirical, quantitative data on such effects. Haber [18] suggested that eusocial, cooperative predators, such as wolves and Cape hunting dogs (Lycaon pictus), should not be hunted at all because they are so poorly suited to exploitation. According to Haber, many terrestrial mammalian herbivores exhibit behaviour that is better suited to exploitation, as their interactions between individuals and generations are relatively simple. Also, because they have existed as prey throughout their evolutionary histories, such species are used to experiencing the disruptive effects of being hunted and then resuming normal activities once they are safe.

The arguments of Haber [18] might also apply to the highly social odontocetes that appear poorly suited to exploitation. The apparent resilience of mysticetes to 
exploitation, at least in comparison to odontocetes, is interesting to contemplate. Mysticetes, like many herbivorous terrestrial mammals, have relatively simple interactions between individuals. Also, mysticetes differ from odontocetes in generally not maintaining long-term social bonds or in not having long periods of dependency after birth. There is little evidence of social bonds in mysticetes other than the relationship between mothers and offspring. These traits, along with their life history, may account for the relatively strong recovery seen in many mysticete populations.

As a final point, we emphasize that our ability to reach firm conclusions regarding the resilience of odontocetes to exploitation are hampered by the shortage of data on population trends. Also, in many cases we lack the necessary information on other, potentially confounding factors, such as hidden mortality (e.g., bycatch) or habitat degradation (e.g., reduced prey populations). Despite the difficulties involved, we stress the importance of monitoring depleted odontocete populations for evidence of recovery, or otherwise, in order to shed further light on the issues raised in this paper.

\section{Acknowledgment}

The authors thank P. Clapham for a thoughtful and helpful review of this paper.

\section{References}

[1] P. B. Best, "Increase rates in severely depleted stocks of baleen whales," ICES Journal of Marine Science, vol. 50, no. 2, pp. 169-186, 1993.

[2] T. A. Branch, K. Matsuoka, and T. Miyashita, "Evidence for increases in Antarctic blue whales based on Bayesian modelling," Marine Mammal Science, vol. 20, no. 4, pp. 726754, 2004.

[3] J. E. Moore and J. Barlow, "Bayesian state-space model of fin whale abundance trends from a 1991-2008 time series of linetransect surveys in the California Current," Journal of Applied Ecology, vol. 48, no. 5, pp. 1195-1205, 2011.

[4] M. P. Heide-Jørgensen, K. Laidre, D. Borchers, F. Samarra, and H. Stern, "Increasing abundance of bowhead whales in West Greenland," Biology letters, vol. 3, no. 5, pp. 577-580, 2007.

[5] S. B. Reilly and J. Barlow, "Rates of increase in dolphin population size," Fishery Bulletin, vol. 84, no. 3, pp. 527-533, 1986.

[6] P. R. Wade, "Calculating limits to the allowable humancaused mortality of cetaceans and pinnipeds," Marine Mammal Science, vol. 14, no. 1, pp. 1-37, 1998.

[7] P. R. Wade, "Population dynamics," in Encyclopedia of Marine Mammals, W. F. Perrin, B. Würsig, and J. G. M. Thewissen, Eds., Academic Press, San Diego, Calif, USA, 2002.

[8] S. L. Mesnick and K. Ralls, "Mating systems," in Encyclopedia of Marine Mammals, W. F. Perrin, B. Würsig, and J. G. M. Thewissen, Eds., Academic Press, San Diego, Calif, USA, 2002.

[9] A. Acevedo-Gutierrez, "Group behaviour," in Encyclopedia of Marine Mammals, W. F. Perrin, B. Würsig, and J. G. M. Thewissen, Eds., Academic Press, San Diego, Calif, USA, 2002.
[10] J. H. Poole, "Rutting behaviour in African elephants: the phenomenon of musth," Behaviour, vol. 102, no. 3-4, pp. 283-316, 1987.

[11] K. McComb, C. Moss, S. M. Durant, L. Baker, and S. Sayialel, "Matriarchs as repositories of social knowledge in African elephants," Science, vol. 292, no. 5516, pp. 491-494, 2001.

[12] J. R. Ginsberg and E. J. Milner-Gulland, "Sex-biased harvesting and population dynamics in ungulates: implications for conservation and sustainable use," Conservation Biology, vol. 8, no. 1, pp. 157-166, 1994.

[13] R. B. Harris, W. A. Wall, and F. W. Allendorf, "Genetic consequences of hunting: what do we know and what should we do?" Wildlife Society Bulletin, vol. 30, no. 2, pp. 634-643, 2002.

[14] C. T. Darimont, S. M. Carlson, M. T. Kinnison, P. C. Paquet, T. E. Reimchen, and C. C. Wilmers, "Human predators outpace other agents of trait change in the wild," Proceedings of the National Academy of Sciences of the United States of America, vol. 106, no. 3, pp. 952-954, 2009.

[15] D. W. Coltman, P. O’Donoghue, J. T. Jorgenson, J. T. Hogg, C. Strobeck, and M. Festa-Bianchet, "Undesirable evolutionary consequences of trophy hunting," Nature, vol. 426, no. 6967, pp. 655-658, 2003.

[16] H. Jachmann, P. S. Berry, and H. Imae, "Tusklessness in African elephants: a future trend," African Journal of Ecology, vol. 33, no. 3, pp. 230-235, 1995.

[17] R. Fergusson, A preliminary investigation of the population dynamics of sable antelope in the Matetsi Safari Area, Zimbabwe [M.S. thesis], University of Zimbabwe, Harare, Zimbabwe, 1990.

[18] G. C. Haber, "Biological, conservation, and ethical implications of exploiting and controlling wolves," Conservation Biology, vol. 10, no. 4, pp. 1068-1081, 1996.

[19] B. L. Taylor, M. Martinez, T. Gerrodette, J. Barlow, and Y. N. Hrovat, "Lessons from monitoring trends in abundance of marine mammals," Marine Mammal Science, vol. 23, no. 1, pp. 157-175, 2007.

[20] H. Whitehead, "Density-dependent habitat selection and the modeling of sperm whale (Physeter macrocephalus) exploitation," Canadian Journal of Fisheries and Aquatic Sciences, vol. 57, no. 1, pp. 223-230, 2000.

[21] L. Weilgart, H. Whitehead, and K. Payne, "A colossal convergence," American Scientist, vol. 84, no. 3, pp. 278-287, 1996.

[22] H. Whitehead and L. Rendell, "Movements, habitat use and feeding success of cultural clans of South Pacific sperm whales," Journal of Animal Ecology, vol. 73, no. 1, pp. 190196, 2004.

[23] S. L. Mesnick, K. Evans, B. L. Taylor, J. Hyde, S. EscorzaTrevino, and A. E. Dizon, "Sperm Whale social structure: why it takes a village to raise a child," in Animal Social Complexity: Intelligence, Culture and Individualized Societies, F. B. M. de Waal and P. L. Tyack, Eds., Harvard University, Cambridge, Mass, USA, 2003.

[24] H. Whitehead, "Babysitting, dive synchrony, and indications of alloparental care in sperm whales," Behavioral Ecology and Sociobiology, vol. 38, no. 4, pp. 237-244, 1996.

[25] H. Whitehead, J. Christal, and S. Dufault, "Past and distant whaling and the rapid decline of sperm whales off the Galapagos Islands," Conservation Biology, vol. 11, no. 6, pp. 1387-1396, 1997.

[26] R. Clarke, A. Aguayo, and O. Paliza, "Pregnancy rates of sperm whales in the southeast Pacific between 1959 and 1962 and a comparison with those from Paita, Peru between 1975 
and 1977," Report of the International Whaling Commission, vol. 2, pp. 151-158, 1980.

[27] S. L. Perry, D. P. DeMaster, and G. K. Silber, "The great whales: history and status of six species listed as endangered under the U.S. Endangered Species Act of 1973," Marine Fisheries Review, vol. 61, no. 1, pp. 1-74, 1999.

[28] J. Barlow, "Recent information on the status of large whales in California waters," NOAA Technical Memorandum NMFS NOAA-TM-NMFS-SWFSC-203, U.S. Department Of Commerce, 1994.

[29] H. Whitehead, "Estimates of the current global population size and historical trajectory for sperm whales," Marine Ecology Progress Series, vol. 242, pp. 295-304, 2002.

[30] R. Clarke, "Open boat whaling in the Azores," Discovery Reports, vol. 26, pp. 281-354, 1954.

[31] International Whaling Commission, "Report of the subcommittee on sperm whales," Report of the International Whaling Commission, vol. 32, pp. 68-86, 1982.

[32] G. O'Corry-Crowe, "Beluga whales," in Encyclopedia of Marine Mammals, W. F. Perrin, B. Würsig, and J. G. M. Thewissen, Eds., Academic Press, San Diego, Calif, USA, 2002.

[33] T. G. Smith, M. O. Hammill, and A. R. Martin, "Herd composition \& behaviour of white whales (Delphinapterus leucas) in two Canadian Arctic estuaries," Meddelelser om. Grønland, Bioscience, vol. 39, pp. 175-186, 1994.

[34] D. E. Sergeant and P. F. Brodie, "Identity, abundance, and present status of populations of white whales, Delphinapterus leucas," Journal of the Fisheries Research Board of Canada, vol. 32, pp. 1047-1054, 1975.

[35] D. E. Sergeant, "On permissible expoitation rates of Monodontidae," Report of the International Whaling Commission, vol. 31, pp. 583-588, 1981.

[36] M. Kingsley, "Population dynamics of the narwhal Monodon monoceros: an initial assessment (Odontoceti: Monodontidae)," Journal of Zoology, vol. 219, no. 2, pp. 201-208, 1989.

[37] R. R. Reeves and E. Mitchell, "Catch history, former abundance, and distribution of white whales in Hudson Strait and Ungava Bay," Naturaliste Canadien, vol. 114, no. 1, pp. 1-65, 1987.

[38] M. P. Heide-Jørgensen, "Distribution, exploitation and population status of white whales (Delphinapterus leucas) and narwhals (Monodon monoceros) in West Greenland," Meddelelser om. Grønland, Bioscience, vol. 39, pp. 135-149, 1994.

[39] E. Mitchell, Porpoise, Dolphin and Small Whale Fisheries of the World: Status and Problems, vol. 3 of IUCN Monograph, International Union for Conservation of Nature and Natural Resources, Morges, Switzerland, 1975.

[40] R. C. Hobbs, D. J. Rugh, and D. P. Demaster, "Abundance of belugas, Delphinapterus leucas, in Cook Inlet, Alaska, 19942000," Marine Fisheries Review, vol. 62, no. 3, pp. 37-45, 2000.

[41] R. C. Hobbs, K. E. W. Shelden, D. J. Vos, K. T. Goetz, and D. J. Rugh, "Status review and extinction assessment of Cook Inlet belugas (Delphinapterus leucas)," Alaska Fisheries Science Center Report AFSC-PR-2006-16, NOAA National Marine Fisheries Service, Seattle, Wash, USA, 2006.

[42] R. R. Reeves and E. Mitchell, "Catch history and initial population of white whales (Delphinapterus leucas) in the river and Gulf of St. Lawrence, eastern Canada," Naturaliste Canadien, vol. 111, no. 1, pp. 63-121, 1984.
[43] M. O. Hammill, L. N. Measures, J.-F. Gosselin, and V. Lesage, "Lack of recovery in St. Lawrence Estuary beluga," Science Advisory Secretariat Research Document 2007/026, 2007.

[44] L. Lowry, G. O'Corry-Crowe, and D. Goodman, "Delphinapterus leucas (Cook Inlet population)," in 2006 IUCN Red List of Threatened Species, IUCN, Gland, Switzerland, 2006.

[45] L. F. Lowry, K. J. Frost, A. Zerbini, D. DeMaster, and R. R. Reeves, "Trend in aerial counts of belugal or white whales (Delphinapterus leucas) in Bristol Bay, Alaska, 1993-2005,” Journal of Cetacean Research and Management, vol. 10, no. 3, pp. 201-207, 2008.

[46] H. B. Gerson and J. P. Hickie, "Head scarring on male narwhals (Monodon monoceros): evidence for aggressive tusk use," Canadian Journal of Zoology, vol. 63, no. 9, pp. 20832087, 1985.

[47] NAMMCO/JCNB, "Annex 1. Joint meeting of the NAMMCO Scientific Committee Working Group on the Population Status of Narwhal and Beluga in the North Atlantic and the Canada/Greenland Joint Commission on Conservtion and Management of Narwhal and Beluga Scientific Working Group, Nuuk, Greenland, 13-16 October 2005,” Annual Report 2005, North Atlantic Marine Mammal Commission, 2006.

[48] M. P. Heide-Jørgensen, "Aerial digital photographic surveys of narwhals, Monodon monoceros, in Northwest Greenland," Marine Mammal Science, vol. 20, no. 2, pp. 246-261, 2004.

[49] M. P. Heide-Jørgensen and M. Acquarone, "Size and trends of the bowhead whale, beluga and narwhal stocks off West Greenland," NAMMCO Scientific Publications, vol. 4, pp. 191-210, 2002.

[50] NAMMCO/JCNB, "Report of the Joint Meeting of the NAMMCO Scientific Committee Working Group on the Population Status of Narwhal and Beluga in the North Atlantic and the Canada/Greenland Joint Commission on Conservation and Management of Narwhal and Beluga Scientific Working Group, Winnipeg, Canada, 17-20 February 2009," Annual Report 2009, North Atlantic Marine Mammal Commission, 2009.

[51] R. R. Reeves, What is a narwhal worth? An analysis of factors driving the narwhal hunt and a critique of tried approaches to hunt management [Ph.D. thesis], McGill University, Montreal, Canada, 1992.

[52] K. L. Laidre and M. P. Heide-Jørgensen, "Arctic sea ice trends and narwhal vulnerability," Biological Conservation, vol. 121, no. 4, pp. 509-517, 2005.

[53] K. Laidre, M. P. Heide-Jørgensen, H. Stern, and P. Richard, "Unusual narwhal sea ice entrapments and delayed autumn freeze-up trends," Polar Biology, vol. 35, pp. 149-154, 2011.

[54] P. F. Olesiuk, M. A. Bigg, and G. M. Ellis, "Life history and population dynamics of resident killer whales (Orcinus orca) in the coastal waters of British Columbia and Washington State," Report of the International Whaling Commission, vol. 12, pp. 209-243, 1990.

[55] R. L. Pitman and P. Ensor, "Three forms of killer whales (Orcinus orca) in Antarctic waters," Journal of Cetacean Research and Management, vol. 5, pp. 131-139, 2003.

[56] J. K. B. Ford, G. M. Ellis, and K. C. Balcomb, Killer Whales: The Natural History and Genealogy of Orcinus orca in British Columbia and Washington, University of Washington, Seattle, Wash, USA, 2nd edition, 2000.

[57] M. A. Bigg, P. F. Olesiuk, G. M. Ellis, J. K. B. Ford, and K. C. Balcomb, "Social organization and genealogy of resident 
killer whales (Orcinus orca) in the coastal waters of British Columbia and Washington State," Report of the International Whaling Commission, vol. 12, pp. 383-405, 1990.

[58] J. K. B. Ford, "Vocal traditions among resident killer whales (Orcinus orca) in coastal waters of British Columbia," Canadian Journal of Zoology, vol. 69, no. 6, pp. 1454-1483, 1991.

[59] H. Yurk, "Do killer whales have culture?" in Animal Social Complexity: Intelligence, Culture, and Individualized Societies, F. B. M. de Waal and P. L. Tyack, Eds., Harvard University, Cambridge, Mass, USA, 2003.

[60] J. C. López and D. López, "Killer whales of Patagonia and their behavior of intentional stranding while hunting nearshore," Journal of Mammalogy, vol. 66, pp. 181-183, 1985.

[61] E. Hoyt, The Whale Called Killer, E P Dutton, New York, NY, USA, 1990.

[62] M. M. Krahn, P. R. Wade, S. T. Kalinowski et al., "Status review of southern resident killer whales (Orcinus orca) under the Endangered Species Act," NOAA Technical Memorandum NMFS NOAA-TM-NMFS-NWFSC-54, U.S. Department Of Commerce, 2002.

[63] J. K. B. Ford, G. M. Ellis, P. F. Olesiuk, and K. C. Balcomb, "Linking killer whale survival and prey abundance: food limitation in the oceans' apex predator?" Biology Letters, vol. 6, no. 1, pp. 139-142, 2010.

[64] P. S. Ross, G. M. Ellis, M. G. Ikonomou, L. G. BarrettLennard, and R. F. Addison, "High PCB concentrations in free-ranging Pacific killer whales, Orcinus orca: effects of age, sex and dietary preference," Marine Pollution Bulletin, vol. 40, no. 6, pp. 504-515, 2000.

[65] M. M. Krahn, M. B. Hanson, R. W. Baird et al., "Persistent organic pollutants and stable isotopes in biopsy samples (2004/2006) from Southern Resident killer whales," Marine Pollution Bulletin, vol. 54, no. 12, pp. 1903-1911, 2007.

[66] M. M. Krahn, M. Bradley Hanson, G. S. Schorr et al., "Effects of age, sex and reproductive status on persistent organic pollutant concentrations in "Southern Resident" killer whales," Marine Pollution Bulletin, vol. 58, no. 10, pp. 1522-1529, 2009.

[67] M. M. Krahn, M. J. Ford, W. F. Perrin et al., "2004 Status review of Southern Resident killer whales (Orcinus orca) under the Endangered Species Act," NOAA Technical Memorandum NMFS NOAA-TM-NMFS-NWFSC-62, U.S. Department Of Commerce, 2004.

[68] P. F. Olesiuk, G. M. Ellis, and J. K. B. Ford, "Life history and population dynamics of northern resident killer whales (Orcinus orca) in British Columbia," DFO Canadian Science Advisory Secretariat Research Document 2005/045, 2005.

[69] C. O. Matkin, E. L. Saulitis, G. M. Ellis, P. Olesiuk, and S. D. Rice, "Ongoing population-level impacts on killer whales Orcinus orca following the "Exxon Valdez" oil spill in Prince William Sound, Alaska," Marine Ecology Progress Series, vol. 356, pp. 269-281, 2008.

[70] D. Lusseau and M. E. J. Newman, "Identifying the role that animals play in their social networks," Proceedings of the Royal Society B, vol. 271, no. 6, pp. S477-S481, 2004.

[71] R. Williams and D. Lusseau, "A killer whale social network is vulnerable to targeted removals," Biology Letters, vol. 2, no. 4, pp. 497-500, 2006.

[72] G. M. Ylitalo, C. O. Matkin, J. Buzitis et al., "Influence of life-history parameters on organochlorine concentrations in free-ranging killer whales (Orcinus orca) from Prince William
Sound, AK," Science of the Total Environment, vol. 281, no. 13, pp. 183-203, 2001.

[73] J. M. Ver Hoef and K. J. Frost, "A bayesian hierarchical model for monitoring harbor seal changes in Prince William Sound, Alaska," Environmental and Ecological Statistics, vol. 10, no. 2, pp. 201-219, 2003.

[74] P. A. Olson and S. B. Reilly, "Pilot whales," in Encyclopedia of Marine Mammals, W. F. Perrin, B. Würsig, and J. G. M. Thewissen, Eds., Academic Press, San Diego, Calif, USA, 2002.

[75] B. Amos, C. Schlotterer, and D. Tautz, "Social structure of pilot whales revealed by analytical DNA profiling," Science, vol. 260, no. 5108, pp. 670-672, 1993.

[76] H. Marsh and T. Kasuya, "Evidence for reproductive senescence in female cetaceans," Report of the International Whaling Commission, vol. 8, pp. 57-74, 1986.

[77] D. Bloch, C. Lockyer, and M. Zachariassen, "Age and growth parameters of the long-finned pilot whale off the Faroe Islands," Report of the International Whaling Commission, vol. 14, pp. 163-207, 1993.

[78] H. Marsh and T. Kasuya, "Changes in the role of a female pilot whale with age," in Dolphin Societies, K. Pryor and K. S. Norris, Eds., University of California, Berkeley, Calif, USA, 1991.

[79] A. D. Foote, "Mortality rate acceleration and postreproductive lifespan in matrilineal whale species," Biology Letters, vol. 4, no. 2, pp. 189-191, 2008.

[80] K. S. Norris and K. Pryor, "Some thoughts on grandmothers," in Dolphin Societies, K. Pryor and K. S. Norris, Eds., University of California, Berkeley, Calif, USA, 1991.

[81] A. Aguilar, L. Jover, and A. Borrell, "Heterogeneities in organochlorine profiles of Faroese long-finned pilot whales: indication of segregation between pods?" Report of the International Whaling Commission, vol. 14, pp. 359-367, 1993.

[82] F. Caurant, C. Amiard-Triquet, and J.-C. Amiard, "Factors influencing the accumulation of metals in pilot whales (Globicephala melas) off the Faroe Islands," Report of the International Whaling Commission, vol. 14, pp. 369-390, 1993.

[83] J. A. Balbuena, F. J. Aznar, M. Fernández, and J. A. Raga, "Parasites as indicators of social structure and stock identity of marine mammals," in Whales, Seals, Fish and Man, A. S. Blix, L. Walløe, and Ø. Ulltang, Eds., Elsevier Science BV, Amsterdam, The Netherlands, 1995.

[84] S. T. Buckland, D. Bloch, K. L. Cattanach et al., "Distribution and abundance of long-finned pilot whales in the North Atlantic, estimated from NASS-1987 and NASS-89 data," Report of the International Whaling Commission, vol. 14, pp. 33-50, 1993.

[85] M. C. Mercer, "Modified Leslie-Delury population models of the long-finned pilot whale (Globicephala melas) and annual production of short-finned squid (Illex illecebrosus) based upon their interaction in Newfoundland," Journal of the Fisheries Research Board of Canada, vol. 32, pp. 11451154, 1975.

[86] K. Hay, "Aerial line-transect estimates of abundance of humpback, fin, and long-finned pilot whales in the Newfoundland-Labrador area," Report of the International Whaling Commission, vol. 32, pp. 475-486, 1982.

[87] D. Nelson and J. Lien, "The status of the long-finned Pilot Whale, Globicephala melas, in Canada," Canadian FieldNaturalist, vol. 110, no. 3, pp. 511-524, 1996. 
[88] D. E. Sergeant, "The biology of the pilot or pothead whale Globicephala melaena (Traill) in Newfoundland waters," Fisheries Research Board of Canada. Bulletin, vol. 132, pp. 184, 1962.

[89] T. Kishiro and T. Kasuya, "Review of Japanese dolphin drive fisheries and their status," Report of the International Whaling Commission, vol. 43, pp. 439-452, 1993.

[90] T. Kasuya, "Japanese whaling and other cetacean fisheries," Environmental Science and Pollution Research, vol. 14, no. 1, pp. 39-48, 2007.

[91] R. C. Connor, R. A. Smolker, and A. F. Richards, "Two levels of alliance formation among male bottlenose dolphins (Tursiops sp.)," Proceedings of the National Academy of Sciences of the United States of America, vol. 89, no. 3, pp. 987990, 1992.

[92] R. C. Connor, M. R. Heithaus, and L. M. Barre, "Complex social structure, alliance stability and mating access in a bottlenose dolphin "super-alliance"," Proceedings of the Royal Society B, vol. 268, no. 1464, pp. 263-267, 2001.

[93] C. A. Rogers, B. J. Brunnick, D. L. Herzing, and J. D. Baldwin, "The social structure of bottlenose dolphins, Tursiops truncatus, in the Bahamas," Marine Mammal Science, vol. 20, no. 4, pp. 688-708, 2004.

[94] K. S. Norris, B. Würsig, R. S. Wells, and M. Würsig, The Hawaiian Spinner Dolphin, University of California, Berkeley, Calif, USA, 1994.

[95] W. F. Perrin, "Using porpoise to catch tuna," World Fishing, vol. 18, pp. 42-45, 1969.

[96] J. Joseph and J. W. Greenough, International Management of Tuna, Porpoise, and Billfish, University of Washington, London, UK, 1979.

[97] S. B. Reilly, M. A. Donahue, T. Gerrodette et al., "Report of the scientific research program under the International Dolphin Conservation Program Act," NOAA Technical Memorandum NMFS NOAA-TM-NMFS-SWFSC-372, U.S. Department Of Commerce, 2005, http://swfsc.noaa.gov/ publications/TM/SWFSC/NOAA-TM-NMFS-SWFSC-372 .PDF.

[98] P. R. Wade, "Revised estimates of incidental kill of dolphins (Delphinidae) by the purse-seine tuna fishery in the eastern tropical Pacific, 1959-1972," Fishery Bulletin, vol. 93, no. 2, pp. 345-354, 1995.

[99] P. R. Wade, G. M. Watters, T. Gerrodette, and S. B. Reilly, "Depletion of spotted and spinner dolphins in the eastern tropical Pacific: modeling hypotheses for their lack of recovery," Marine Ecology Progress Series, vol. 343, pp. 1-14, 2007.

[100] K. Pryor and I. K. Shallenberger, "Social structure in spotted dolphins (Stenella attenuata) in the tuna purse seine fishery in the eastern tropical Pacific," in Dolphin Societies, K. Pryor and K. S. Norris, Eds., University of California, Berkeley, Calif, USA, 1991.

[101] T. Gerrodette and J. Forcada, "Non-recovery of two spotted and spinner dolphin populations in the eastern tropical Pacific Ocean," Marine Ecology Progress Series, vol. 291, pp. 1-21, 2005.

[102] F. Archer, T. Gerrodette, A. Dizon, K. Abella, and S. Southern, "Unobserved kill of nursing dolphin calves in a tuna purseseine fishery," Marine Mammal Science, vol. 17, no. 3, pp. 540-554, 2001.

[103] P. C. Perkins and E. F. Edwards, "Capture rate as a function of school size in pantropical spotted dolphins, Stenella attenuata, in the eastern tropical Pacific Ocean," Fishery Bulletin, vol. 97, no. 3, pp. 542-554, 1999.

[104] B. E. Curry, "Stress in mammals: the potential influence offishery-induced stress on dolphins in the eastern tropical Pacific Ocean," NOAA Technical Memorandum NMFS NOAA-TM-NMFS-SWFSC-260, U.S. Department Of Commerce, 1994.

[105] W. L. Perryman and T. C. Foster, "Preliminary report of predation by small whales, mainly the false killer whale, Pseudorca crassidens, on dolphins (Stenella spp and Delphinus delphis) in the eastern tropical Pacific," NOAA Admin Report LJ-80-05, La Jolla, Calif, USA, 1980.

[106] E. F. Edwards, "Duration of unassisted swimming activity for spotted dolphin (Stenella attenuata) calves: implications for mother-calf separation during tuna purse-seine sets," Fishery Bulletin, vol. 104, no. 1, pp. 125-135, 2006.

[107] S. R. Noren and E. F. Edwards, "Physiological and behavioral development in delphinid calves: implications for calf separation and mortality due to tuna purse-seine sets," Marine Mammal Science, vol. 23, no. 1, pp. 15-29, 2007.

[108] F. Archer, T. Gerrodette, S. Chivers, and A. Jackson, "Annual estimates of the unobserved incidental kill of pantropical spotted dolphin (Stenella attenuata attenuata) calves in the tuna purse-seine fishery of the eastern tropical Pacific," Fishery Bulletin, vol. 102, no. 2, pp. 233-244, 2004.

[109] W. F. Perrin and S. L. Mesnick, "Sexual ecology of the spinner dolphin, Stenella longirostris: geographic variation in mating system," Marine Mammal Science, vol. 19, no. 3, pp. 462-483, 2003.

[110] K. L. Cramer, W. L. Perryman, and T. Gerrodette, "Declines in reproductive output in two dolphin populations depleted by the yellowfin tuna purse-seine fishery," Marine Ecology Progress Series, vol. 369, pp. 273-285, 2008.

[111] P. B. Best, P. A. S. Canham, and N. MacLeod, "Patterns of reproduction in sperm whales, Physeter macrocephalus," Report of the International Whaling Commission, vol. 6, pp. 51-79, 1984.

[112] A. J. Read and P. R. Wade, "Status of marine mammals in the United States," Conservation Biology, vol. 14, no. 4, pp. 929940, 2000.

[113] A. J. Read, "The looming crisis: interactions between marine mammals and fisheries," Journal of Mammalogy, vol. 89, no. 3, pp. 541-548, 2008.

[114] A. J. Read, P. Drinker, and S. Northridge, "Bycatch of marine mammals in U.S. and global fisheries," Conservation Biology, vol. 20, no. 1, pp. 163-169, 2006.

[115] T. J. O’Shea and R. L. Brownell, “Organochlorine and metal contaminants in baleen whales: a review and evaluation of conservation implications," Science of the Total Environment, vol. 154, no. 2-3, pp. 179-200, 1994.

[116] M. Lebeuf, B. Gouteux, L. Measures, and S. Trottier, "Levels and temporal trends (1988-1999) of polybrominated diphenyl ethers in beluga whales (Delphinapterus leucas) from the St. Lawrence Estuary, Canada," Environmental Science and Technology, vol. 38, no. 11, pp. 2971-2977, 2004.

[117] P. J. Clapham and R. L. Brownell, "The potential for interspecific competition in baleen whales," Report of the International Whaling Commission, vol. 46, pp. 361-367, 1996.

[118] G. Bearzi, S. Agazzi, J. Gonzalvo et al., "Overfishing and the disappearance of short-beaked common dolphins from western Greece," Endangered Species Research, vol. 5, no. 1, pp. 1-12, 2008. 

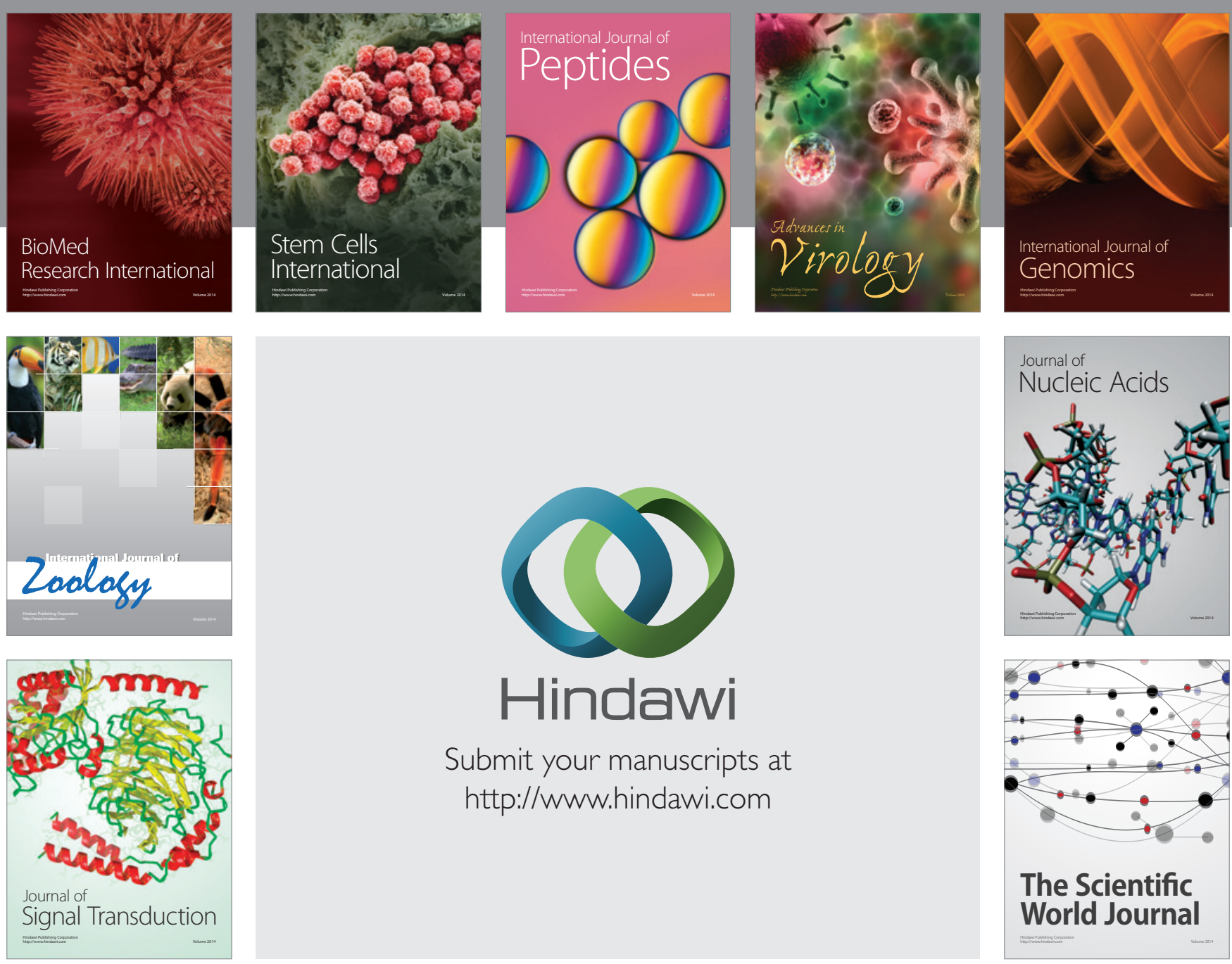

Submit your manuscripts at

http://www.hindawi.com
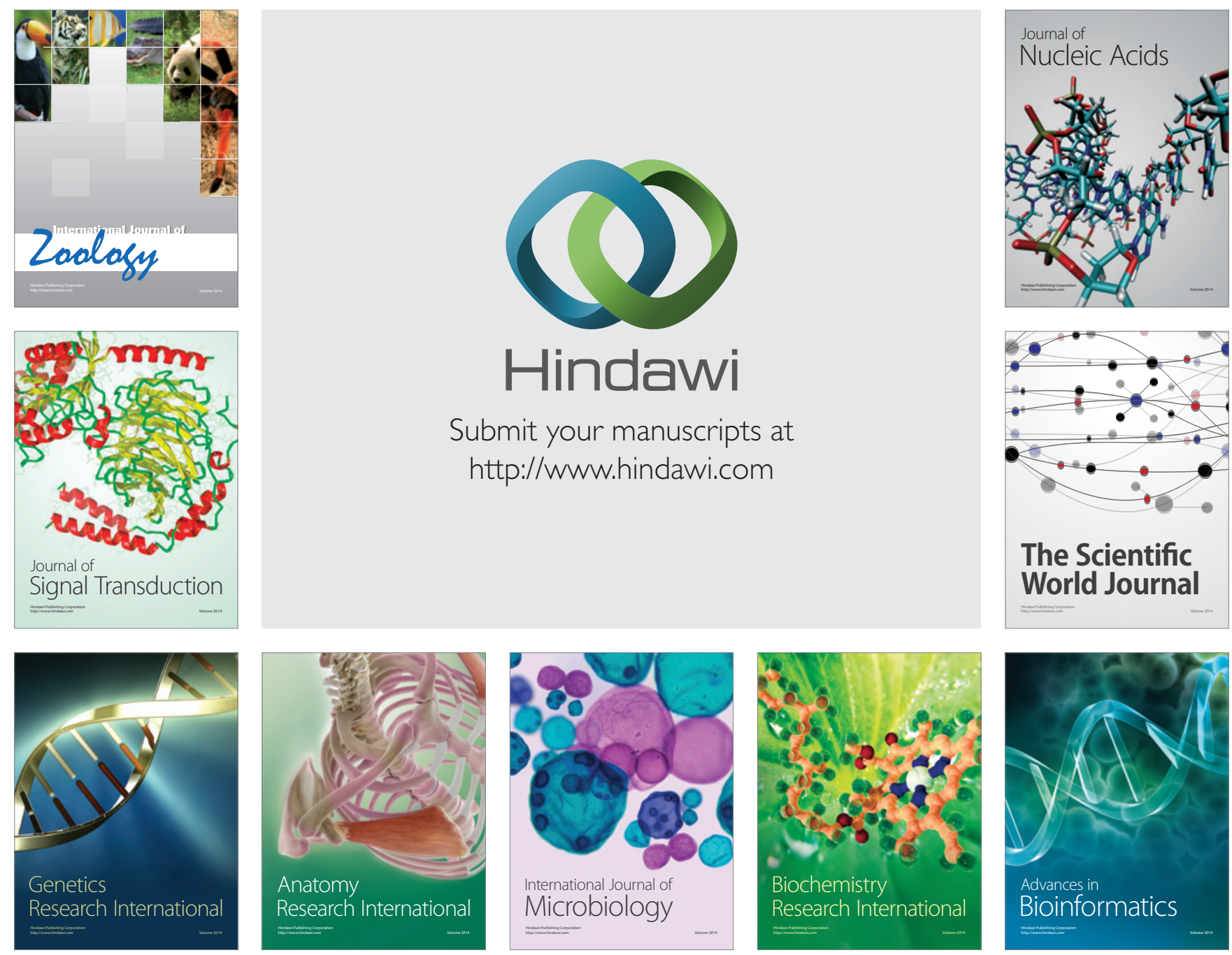

The Scientific World Journal
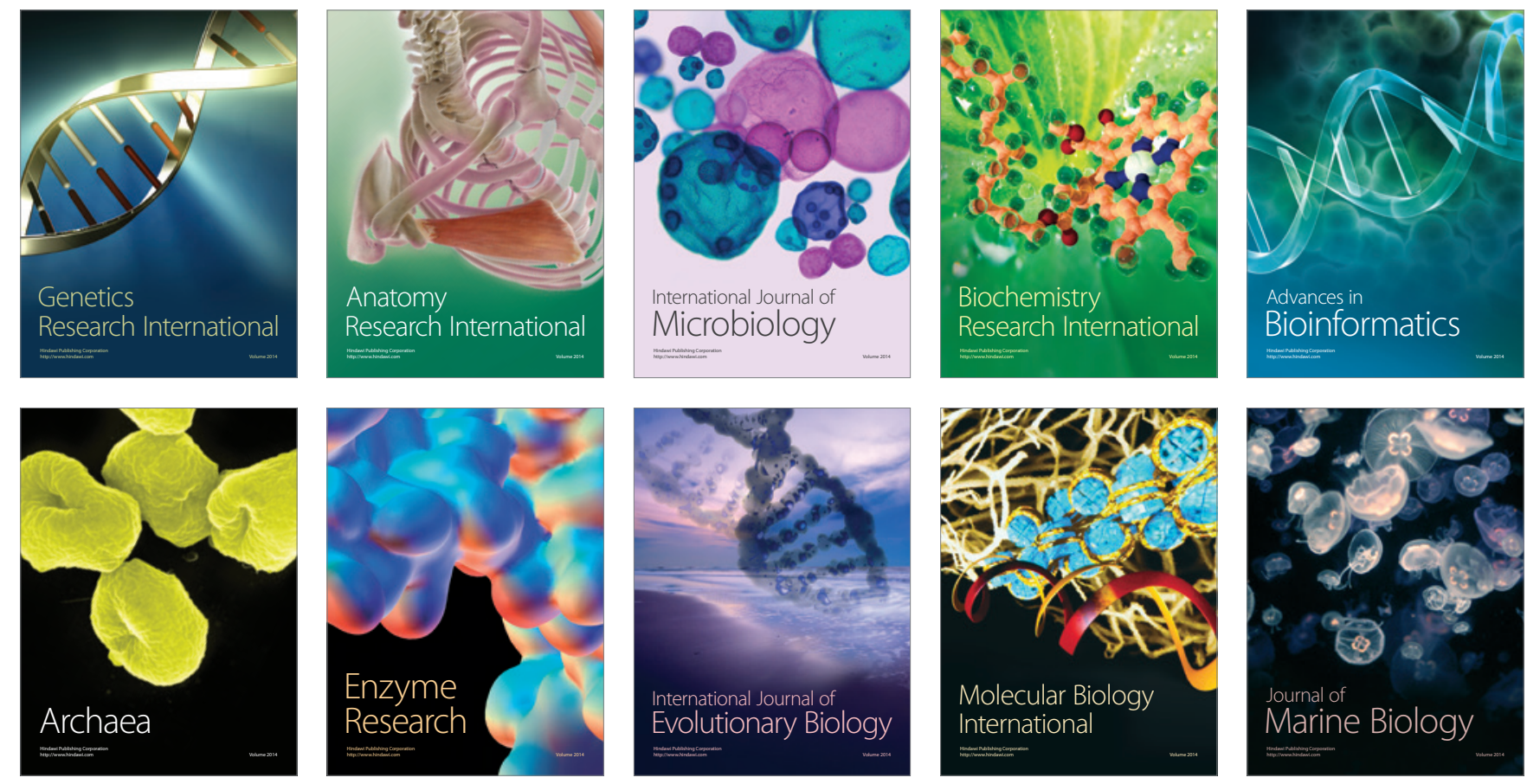